\title{
Article \\ Distinct Signatures of Genomic Copy Number Variants Define Subgroups of Merkel Cell Carcinoma Tumors
}

\author{
Natasha T. Hill ${ }^{1}\left(\right.$, David Kim ${ }^{2}$, Klaus J. Busam ${ }^{3}$, Emily Y. Chu ${ }^{4}$, Clayton Green ${ }^{2}$ and Isaac Brownell ${ }^{1, * *(1)}$ \\ 1 Dermatology Branch, National Cancer Institute, NIH, Bethesda, MD 20892, USA; natasha.hill@nih.gov \\ 2 Marshfield Center, Marshfield, WI 02050, USA; kim.seung@marshfieldclinic.org (D.K.); \\ clayton_green@urmc.rochester.edu (C.G.) \\ 3 Department of Pathology, Memorial Sloan Kettering Cancer Center, New York, NY 10065, USA; \\ busamk@MSKCC.ORG \\ 4 Deprtment of Dermatology, Perelman School of Medicine at the University of Pennsylvania, \\ Philadelphia, PA 19104, USA; Emily.Chu@uphs.upenn.edu \\ * Correspondence: isaac.brownell@nih.gov
}

check for

updates

Citation: Hill, N.T.; Kim, D.; Busam, K.J.; Chu, E.Y.; Green, C.; Brownell, I. Distinct Signatures of Genomic Copy Number Variants Define Subgroups of Merkel Cell Carcinoma Tumors. Cancers 2021, 13, 1134. https:// doi.org/10.3390/cancers13051134

Academic Editors: Virve Koljonen; Weng-Onn Lui and Jürgen C. Becker

Received: 25 January 2021

Accepted: 3 March 2021

Published: 6 March 2021

Publisher's Note: MDPI stays neutral with regard to jurisdictional claims in published maps and institutional affiliations.

Copyright: (C) 2021 by the authors Licensee MDPI, Basel, Switzerland. This article is an open access article distributed under the terms and conditions of the Creative Commons Attribution (CC BY) license (https:// creativecommons.org/licenses/by/ $4.0 /)$.
Simple Summary: Cancer results from genetic changes in cells. These changes are often mutations that alter the DNA sequence of critical genes. However, duplications and deletions in cancer-related genes can also contribute to malignant transformation. In this study we use Nanostring technology to assess DNA copy number changes in samples of Merkel cell carcinoma (MCC), a rare and aggressive neuroendocrine skin tumor. We were able to identify recurrent amplifications and deletions in cancer-related genes. We also found that MCC tumors grouped into three distinct copy number variant profiles. The first group consisted of tumors with multiple deletions. The second group contained tumors with low levels of genomic structural alterations. The last group comprised tumors containing multiple amplifications. Our study suggests that most MCC tumors are associated with deletions in cancer-related genes or are lacking in copy number changes, whereas a small percentage of tumors are associated with genomic amplifications.

Abstract: Merkel cell carcinoma (MCC) is a rare, aggressive neuroendocrine skin cancer. Most MCC tumors contain integrated Merkel cell polyomavirus DNA (virus-positive MCC, VP-MCC) and carry a low somatic mutation burden whereas virus-negative MCC (VN-MCC) possess numerous ultraviolet-signature mutations. In contrast to viral oncogenes and sequence mutations, little is known about genomic structural variants in MCC. To identify copy number variants in commonly altered genes, we analyzed genomic DNA from 31 tumor samples using the Nanostring nCounter copy number cancer panel. Unsupervised clustering revealed three tumor groups with distinct genomic structural variant signatures. The first cluster was characterized by multiple recurrent deletions in genes such as RB1 and WT1. The second cluster contained eight VP-MCC and displayed very few structural variations. The final cluster contained one VP-MCC and four VN-MCC with predominantly genomic amplifications in genes like MDM4, SKP2, and KIT and deletions in TP53. Overall, VN-MCC contained more structure variation than VP-MCC but did not cluster separately from VP-MCC. The observation that most MCC tumors demonstrate a deletion-dominated structural group signature, independent of virus status, suggests a shared pathophysiology among most VP-MCC and VN-MCC tumors.

Keywords: Merkel cell carcinoma; virus positive Merkel cell carcinoma; virus negative Merkel cell carcinoma and copy number variant

\section{Introduction}

Merkel cell carcinoma (MCC) is a rare neuroendocrine skin cancer associated with advanced age, UV-damage, and immunosuppression [1-3]. MCC is an aggressive cancer, with a lethality rate of over one-third, and thus is more deadly than malignant melanoma [1,3-5]. 
The incidence of MCC has increased in the past several decades in part due to improved diagnostic tools, increased clinical awareness, an aging population, and increased sun exposed skin [2,3]. In the United States, approximately 50-80\% of MCC tumors are Merkel cell polyomavirus-positive (VP-MCC), with clonal integration of viral DNA into the host genome [6-12]. VP-MCC tumors carry a low somatic mutation burden, suggesting that tumorigenesis is driven by viral $\mathrm{T}$ antigen oncogenes [11,13-19]. The remaining $20-50 \%$ of MCC tumors are polyomavirus-negative (VN-MCC) and possess numerous ultraviolet signature mutations in genes such as p53 and RB1 [6,8-16]. Although a number of molecular and cytogenetic alterations have been reported for $\mathrm{MCC}$, no unique signatures have been identified [11,13-16,20,21].

Genomic instability can initiate cancers, contribute to disease progression and impact patient response to treatment [22-24]. Several factors promote genomic instability leading to genomic structural variants in the form of amplifications or deletions, such as telomere damage, epigenetic modifications and DNA damage [22,23]. Here we use Nanostring's nCounter copy number variant (CNV) analysis to identify commonly amplified or deleted cancer-related genes in MCC. Unsupervised clustering identified three tumor groups with distinct genomic structural variant signatures. On average VP-MCC tumors had fewer copy number changes than VN-MCC. Furthermore, the cluster of tumors characterized by very few structural variants were all VP-MCC. In contrast, the tumors with numerous copy number variants clustered independently of virus status, suggesting a shared genomic instability among VN-MCC and a subset of VP-MCC.

\section{Results}

\subsection{Three Genomic Structural Variant Signatures Identified in MCC Tumors}

Despite the importance of genomic integrity in cancer, little is known about the genomic structural variants that lead to MCC. Therefore, we sought to identify commonly amplified or deleted cancer genes in MCC. We obtained 31 MCC tumors from Memorial Sloan Kettering (MSK), Marshfield Clinic (MF), and the University of Pennsylvania (UP) (Table 1). The patients ranged from 53 to 100 years of age. Most of the tumors analyzed were obtained from primary tumor lesions on sun exposed skin (Table 1). Genomic DNA from tumor samples and control tissues was analyzed using Nanostring Technologies copy number variant cancer panel assay. Fresh-frozen tumors from MSK were normalized to fresh-frozen adjacent tissue samples, whereas FFPE tumors were normalized to FFPE normal spleen samples. As depicted in Figure 1, unsupervised clustering identified three distinct structural variant groups. Tumors clustered in group 1 (Del) displayed numerous recurrent deletions in a number of genes, including genes involved in cycle regulation such as RB1 (Figure 1 and Table S1). Tumors in group 2 (Low) showed very few genomic structural variations. In the third group (Amp), tumors carried very few deletions but contained numerous recurrent amplifications in several genes, including MDM4, AKT3, $B C L 2 L 1$ and MYCL1 (Figure 1 and Table S1). In this cohort of 31 MCC tumors, most of the tumors $(18,58 \%)$ have the structural group 1 Del signature dominated by deletions in cancer related genes. Group 2 Low with few changes accounted for $8(26 \%)$ tumors, whereas only $5(16 \%)$ tumors had the amplification-heavy group 3 Amp signature. 
Table 1. Patient Summary.

\begin{tabular}{|c|c|c|c|c|c|c|c|}
\hline $\begin{array}{c}\text { MCC } \\
\text { Sample }\end{array}$ & Sex & $\begin{array}{c}\text { MCPyV } \\
\text { Status }\end{array}$ & Age & Site of MCC & $\begin{array}{l}\text { Specimen } \\
\text { Code }\end{array}$ & Cluster & $\begin{array}{l}\text { Tissue } \\
\text { Source }\end{array}$ \\
\hline MF1 & Female & Negative & 68 & right upper arm & primary & Del & FFPE \\
\hline MF2 & Male & Negative & 72 & left hand & primary & Del & FFPE \\
\hline MF3 & Female & Negative & 80 & right gluteal & primary & Del & FFPE \\
\hline MF4 & Male & Negative & 64 & abdominal wall & primary & Del & FFPE \\
\hline MF5 & Male & Negative & 89 & left ala of nose & primary & Del & FFPE \\
\hline MF6 & Male & Negative & - & frontal scalp & primary & Amp & FFPE \\
\hline MF7 & Female & Negative & 94 & right scalp & primary & Del & FFPE \\
\hline MF8 & Female & Negative & - & lymph node & metastasis & Del & FFPE \\
\hline MF9 & Male & Positive & 58 & left thigh & primary & Del & FFPE \\
\hline MF10 & Male & Positive & 67 & left index finger & primary & Del & FFPE \\
\hline MF11 & Male & Negative & 72 & left cheek & primary & Del & FFPE \\
\hline MF12 & Male & Positive & - & right neck & primary & Del & FFPE \\
\hline MF13 & Female & Negative & - & right leg & primary & Del & FFPE \\
\hline MF14 & Female & Negative & 100 & right forehead & primary & Del & FFPE \\
\hline MF15 & Male & Negative & 93 & left cheek, nose & primary & Amp & FFPE \\
\hline MF16 & Female & Negative & 74 & left buttock & primary & Del & FFPE \\
\hline MF18 & Female & Negative & - & right forearm & primary & Del & FFPE \\
\hline MF19 & Male & Negative & 77 & right face & metastasis & Del & FFPE \\
\hline MF20 & Male & Positive & 75 & top of head & primary & Del & FFPE \\
\hline MF21 & Male & Negative & 87 & right wrist & primary & Amp & FFPE \\
\hline MF22 & Female & Negative & 88 & forehead & primary & Amp & FFPE \\
\hline MF23 & Male & Positive & 81 & left cheek & primary & Del & FFPE \\
\hline UP1 & Female & Positive & 75 & left brow & - & Amp & FFPE \\
\hline MSK1 & Female & Positive & 80 & lymph nodes & metastasis & Low & Frozen \\
\hline MSK2 & Male & Positive & 73 & pancreas & metastasis & Low & Frozen \\
\hline MSK6 & Male & Positive & 53 & groin & metastasis & Low & Frozen \\
\hline MSK13 & Female & Positive & 62 & skin & primary & Low & Frozen \\
\hline MSK19 & Male & Positive & 59 & skin & primary & Low & Frozen \\
\hline MSK20 & Female & Positive & 63 & skin & primary & Low & Frozen \\
\hline MSK21 & Male & Positive & 87 & skin & primary & Low & Frozen \\
\hline MSK24 & Male & Positive & 82 & lymph nodes & metastasis & Low & Frozen \\
\hline
\end{tabular}




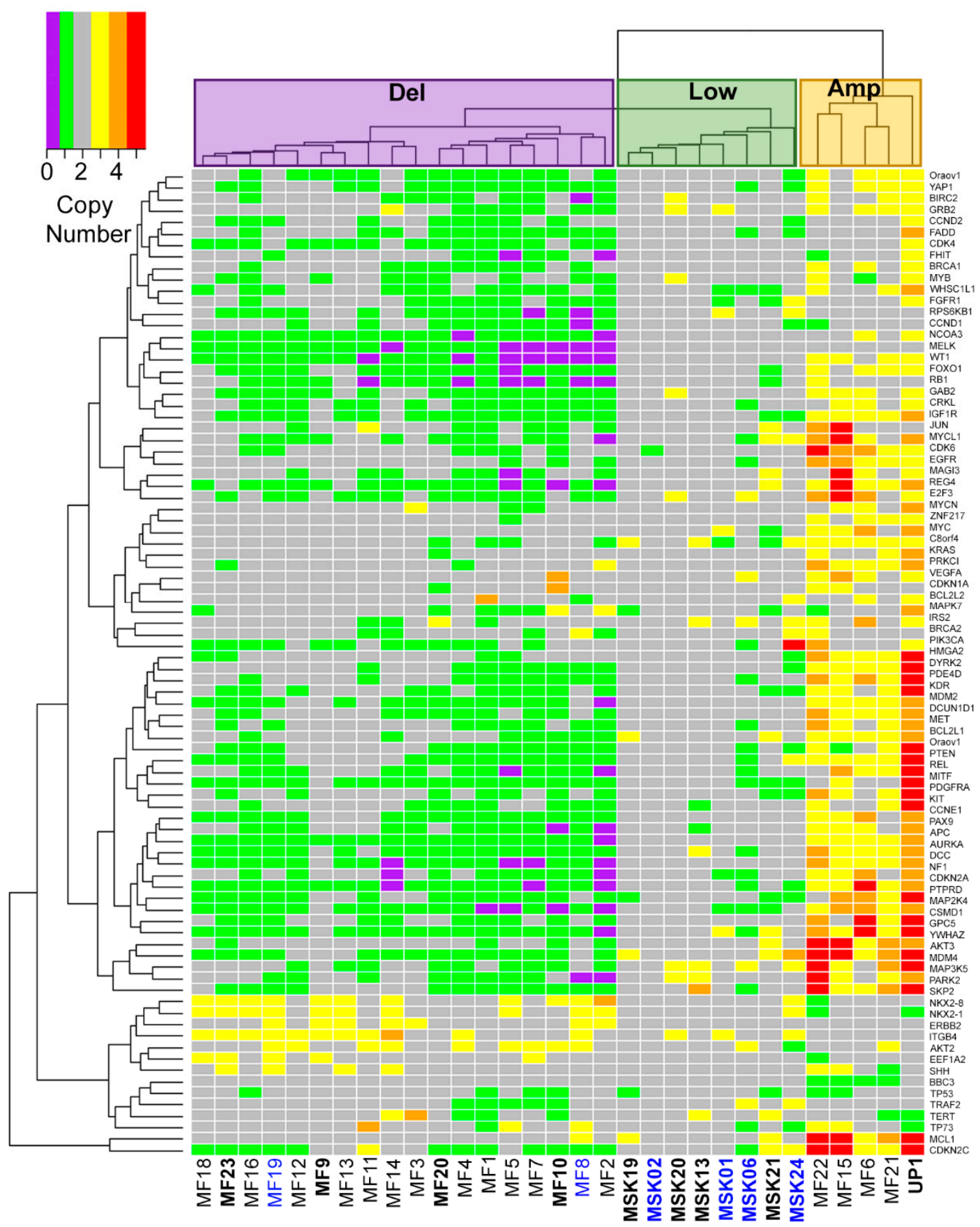

Figure 1. Three genomic structural variant signatures detected in MCC tumors by NanoString nCounter. Tumor DNA from 31 patients with MCC from Memorial Sloan Kettering (MSK), Marshfield Clinic (MF), and the University of Pennsylvania (UP) were subjected to Nanostring nCounter CNV analysis. CNV alterations for 86 gene loci commonly altered in cancer were ascertained and plotted as a heatmap. Three cluster groups denoted as Del (deletion) for group 1, Low for group 2 , and Amp (amplification) for group 3. Bold indicates virus positive MCC (VP-MCC) tumors. Blue indicates metastatic tumor.

\subsection{Structural Variant Signatures Are Characterized by Deletions, Absence of Copy Changes, or Amplifications}

To characterize the differences between MCC structural variant groups we compared the total number of copy number variations per tumor for each cluster. Tumors in both the Del and Amp groups had significantly more CNVs per tumor than tumors in the Low group $(p<0.0001$, Figure 2A). We then compared the average sum of the allelic variation relative to diploid ( -1 for each allelic deletion, +1 for each amplification, total of 86 genes) for the 
tumors in each cluster. As seen in Figure 2B, the Del group tumors had the lowest average sum of variation ( -37 copies), reflective of their numerous deletions. Similarly, the Low group tumors' average sum of variation was 0.125 copies, close to the zero-value seen in the control samples; and the Amp group had an average sum of 82 copies. The significant difference in the average sums of variation $(p<0.0001)$ support there being 3 distinct $\mathrm{CNV}$ profiles for MCC rather than random distributions of deletions and amplifications in the tumors.

(A)
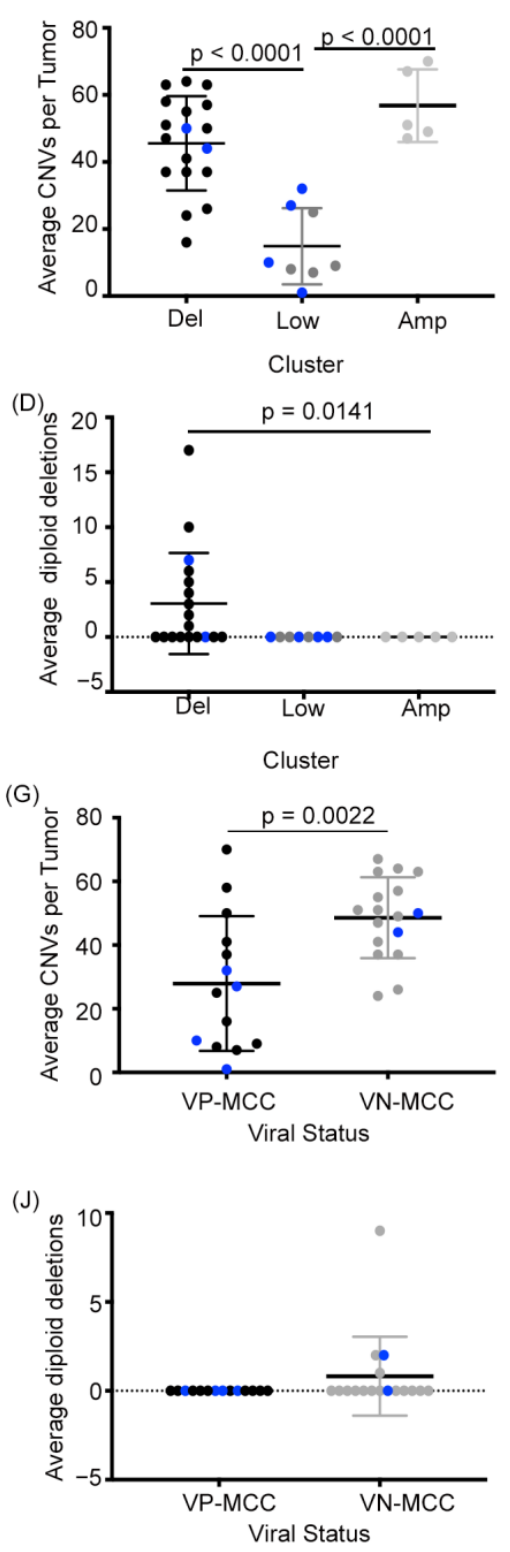

(B)

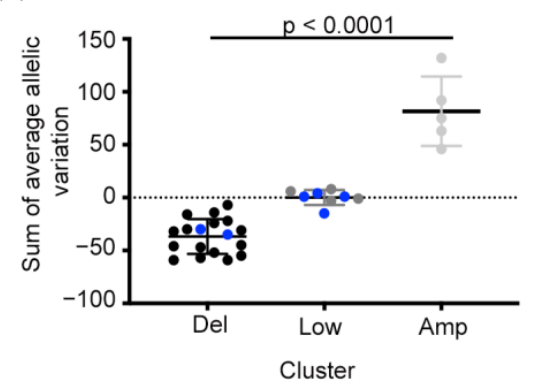

(E)

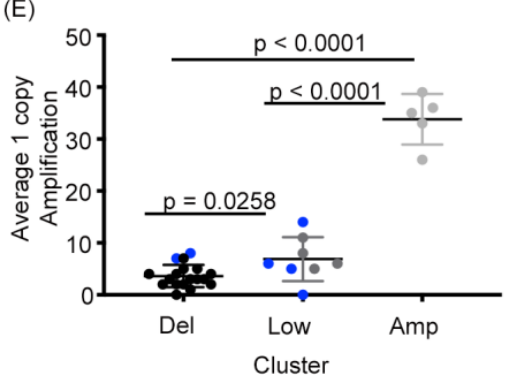

(H)

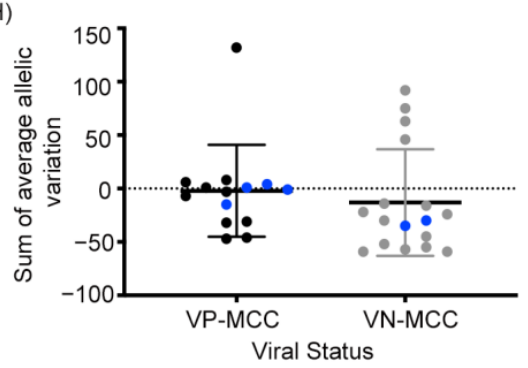

(K)

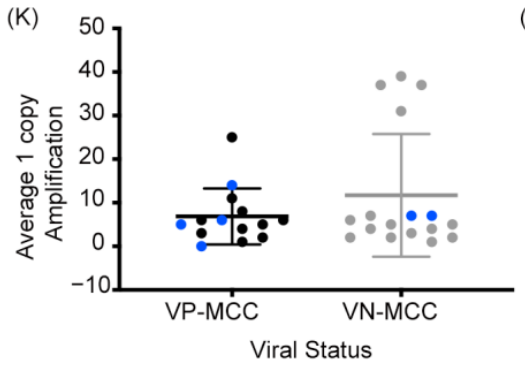

(C)

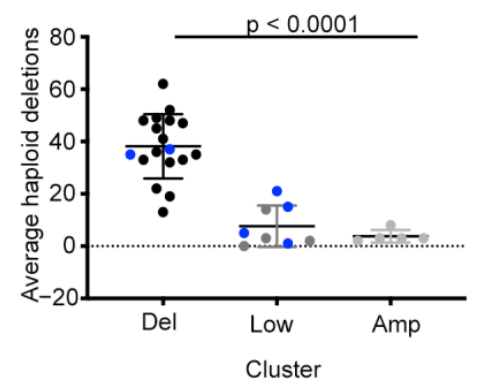

(F)
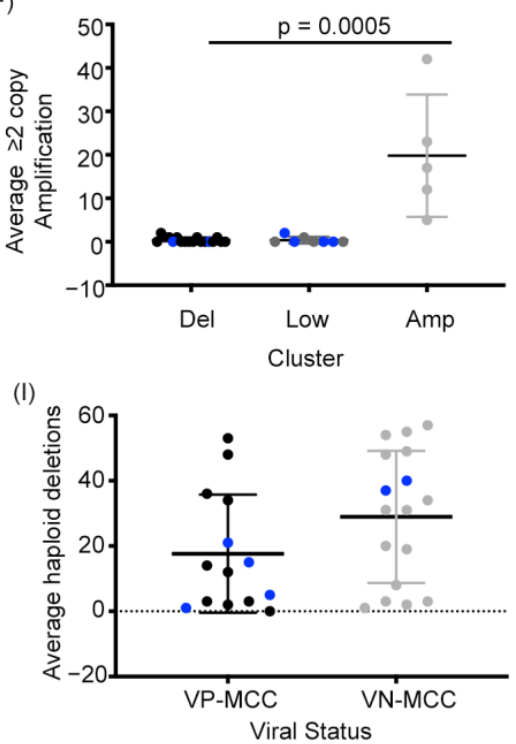

(L)

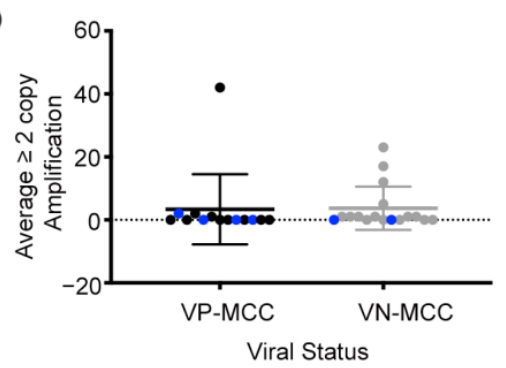

Figure 2. Structural variant clusters show distinct levels and types of CNVs whereas VN-MCC show more structural variation than VP-MCC. Comparison of clusters for the (A) average number of CNVs per tumor (one-way ANOVA), (B) average sum of allelic variations ( -1 for each haploid deletion, +1 for each amplification, Kruskal-Wallis test), (C) average haploid deletions (Kruskal-Wallis test), (D) average diploid deletions (Kruskal-Wallis test), (E) average single-copy amplification (one-way ANOVA), and (F) average two or greater copy amplifications (Kruskal-Wallis test). Comparison between VP-MCC and VN-MCC for the $(\mathbf{G})$ average number of CNVs per tumor (unpaired T-test), $(\mathbf{H})$ average s um of allelic variations (MannWhitney test), (I) average haploid deletions (unpaired T-test), (J) average diploid deletions (Mann-Whitney test), (K) average single-copy amplification (Mann-Whitney test), and (L) average two or greater copy amplifications (Mann-Whitney test). Uncolored dots are primary tumor samples, blue dots indicate metastatic tumor samples. 
A similar trend between signature groups was seen when quantifying $\mathrm{CNV}$ on a per gene level with haploid deletions being more common than diploid deletions, and single copy amplifications being more common than multi copy amplifications (Figure 2C-F). Taken together, quantitative comparisons between the three structural variant signatures suggest that MCC tumors with genetic instability are dominated by either recurrent haploid deletions or recurrent amplifications in cancer associated genes.

\subsection{VN-MCC Contains More Structural Variants Than VP-MCC}

Comparing the average CNV per tumor for VP-MCC and VN-MCC samples we found that VN-MCC tumor samples contained significantly more structural variation per tumor (48.6) than VP-MCC samples (27.9) (Figure 2G). This is consistent with prior studies that also found higher rates of CNV in VN-MCC [21,25]. Interestingly, VP-MCC and VN-MCC showed no difference in the average sum of the variation, haploid deletions, diploid deletions, single copy amplifications, or multi copy amplifications (Figure 2H-L). Thus, although VN-MCC have more structural variants than VP-MCC on average, each virus status subtype contains similar frequencies of amplifications and deletions. The decreased average CNV count for VP-MCC was largely due to the fact that the eight tumors with the Low variant signature were exclusively VP-MCC. Accordingly, the structural variant signature of MCC tumors correlated with tumor virus status (two-tailed Fisher exact test, $p<0.005)$, with VP-MCC being more likely in the Low variant group and VN-MCC more likely in the deleted or amplified group. However, if a tumor was not in the Low variant group, the likelihood of having a deletion or amplification signature was independent of virus status $(p=1.0)$.

\subsection{Structural Variant Signatures Are Not Predictors of Survival}

The three distinct CNV signatures observed in MCC tumors suggest differences in their biology that might impact disease progression. We used non-parametric Kaplan-Meier estimate to test for overall survival differences in patients based on the CNV signatures of their MCC tumors. Survival data was available for 29 of the 31 patients in the study. As shown in Figure S1, Kaplan-Meier survival estimates indicate that there is no statistical difference in survival between the three signature groups $(p<0.8857)$. Taken together, although the three signature groups reflect distinct patterns of genomic instability, any difference in survival was not detected in this cohort of patients.

\section{Discussion}

Merkel cell carcinoma generally arises on sun exposure skin, giving rise to the notion that UV mediated damage induces MCC [26-29]. UV-induced DNA damage is frequently seen in skin cancer and has been shown to cause genomic instability [30-36]. Oncoviruses also leads to genomic instability via virus integration or through the expression of viral oncogenes that alters the fidelity of replication [37]. Interestingly, although VP-MCC tumors do not have a significant enrichment of UV-induced sequence mutations, these tumors primarily occur on sun exposed regions of the skin and these tumors, like VN-MCC, also show genomic instability $[21,25,38]$. Here we used Nanostring Technologies nCounter system to examine the frequency of structural variation in 31 MCC tumors by quantifying amplifications and deletions in 86 cancer related genes. A number of the alterations found in our data are predicted to disrupt cell cycle regulation, including deletions of RB1. Deletions in the RB1 locus or mutations that functionally inactive RB have been previously identified in MCC [11,13,15,21]. Loss of RB function is a well-established phenotype in a variety of cancers [39-44]. In VP-MCC the MCPyV large T antigen binds and inhibits RB, thereby releasing E2F to promote G1 to $S$ phase transition through the cell cycle [45-47]. Interestingly, 5 (36\%) of 14 VP-MCC also showed deletions in RB1, suggesting redundant inactivation of RB may play a role in either MCC onset or progression. Future studies to determine whether CNVs in RB1 correlate with the presence or absence of specific sequence mutations may lead to a better understand of the pathophysiology of this disease. 
Genomic amplifications can also dysregulate the cell cycle leading to tumorigenesis $[23,48,49]$. Our data shows numerous amplifications within the group 3 Amp cluster, some of which are well established proto-oncogenes known to be involved in the onset and progression of many different cancers. Specifically, we observed amplifications in MYCL1 which was previously shown to me amplified in MCC $[20,21,50]$. Furthermore, the protein levels of MYC, which was also a gene loci amplified in the group 3 cluster, are stabilized in VP-MCC by the small $\mathrm{T}$ antigen binding and inhibiting the function of the F-box protein FBW7 [17]. In small cell lung cancer (SCLC), another neuroendocrine carcinoma, L-myc is thought to induce pre-rRNA synthesis and transcriptional pathways concomitant with ribosomal biogenesis [51]. A similar pathogenesis may be exploited in L-myc amplified MCC. Another interesting finding in our data is that tumors in the Amp signature cluster showed amplifications in AKT3 whereas tumors with the Del signature had amplifications in $A K T 2$, suggesting that both tumor types may utilize the AKT survival pathway for tumorigenesis. Inhibition of the AKT downstream target mTOR has already been implicated as a potential target for the treatment of MCC [52,53]. Moreover, gene mutations and amplification in AKT1 have been found in MCC through next generation sequencing studies [14,21]. Multiple lines of evidence suggestion that both L-myc and AKT could potentially be druggable targets in the treatment of MCC [14,50,51], and assessing CNV signature type may help predict which MCC tumors are more likely to respond to these treatments.

We observed a number of genomic structural variants previously unreported in MCC. Most notably, recurrent deletions of fragile histidine triad (FHIT) and recurrent amplifications in integrin $\beta 4$ (ITG $\beta 4$ ). Interestingly, FHIT was shown to inhibit AKT activation leading to one mechanism by which FHIT decreases lung cancer cell survival $[54,55]$. Additionally, FHIT was shown to transcriptionally repress $\beta$-catenin [56], which is a downstream target of not only AKT but also of the WNT signaling pathway $[57,58]$. The deletions observed in FHIT could further implicate AKT in MCC. Intriguingly, ITG $\beta 4$ promotes metastasis through the induction of epithelial-mesenchymal transition in pancreatic ductal adenocarcinoma [59]. In addition, expression of ITG $\beta 4$, CD24 and Notch were shown to confer non-small cell lung carcinoma (NSCLC) propagation in clonogenic and othotoptic transplantation assays [60]. In MCC, amplification in ITG $\beta 4$ might similarly promote proliferation and metastasis. Taken together, structural alterations in MCC tumors potentially alter a number of different pathways to increase tumor cells survival such as AKT, L-myc, $\mathrm{RB}$, and $\beta$-catenin. Additionally, structural variation in ITG $\beta 4$ could play a role in MCC metastases. Further work will be needed to test these potential associations.

The Nanostring technology used in this study allows for direct quantification of fragmented genomic DNA based on hybridization to barcoded probes for genes commonly amplified or deleted in cancers. The technology uses an average of 3 probes per gene, internal control probes to 54 invariant genomic regions, as well as spike-in process controls. Thus, copy number variants relative to similarly processed diploid control tissues can be reproducibly quantified from either FFPE or fresh-frozen tumor samples [61]. The heterogeneity of analyzing both FFPE and fresh-frozen samples from different institutions is a limitation of our study. It is noteworthy that the 8 tumors comprising the Low CNV cluster were all fresh-frozen samples from Memorial Sloan-Kettering, whereas the tumors in the Del and Amp clusters were FFPE samples. Although the fresh-frozen samples and controls met the same quality control endpoints as the FFPE samples and controls, it is possible that there were batch effects related to sample acquisition or fixation. Formalin fixation can cause DNA fragmentation, degradation, crosslinking, and adduct formation that can theoretically impact molecular studies [62]. In addition, unlike the FFPE controls, the fresh-frozen controls were normal adjacent tissues collected at the time of tumor excisions. Normal adjacent tissue has limitations as a control, but it is generally found to contain diploid DNA [63] and thus its use is unlikely to impact a pooled reference for $\mathrm{CNV}$ normalization. Despite these concerns, as discussed above, many of the recurrent CNVs observed in our study were previously reported in MCC tumors based on studies 
using other copy number assays $[11,13-15,20,21,50]$, suggesting some accuracy in our data. Similarly, the observation that the average CNV load in VN-MCC is higher than the average for VP-MCC has also been reported in other studies $[11,13,21]$. Finally, our finding that individual VP-MCC tumors can have very few structural variants or can contain multiple amplifications or deletions is consistent with the results of Starrett et al., 2020 [21]. Nonetheless, the possibility that some artifact is contributing to the clustering of our data must be considered. Therefore, further studies will be needed to validate our findings and explore the functional implications of MCC tumors with different structural variant signatures.

\section{Materials and Methods}

\subsection{Inclusion Criteria and Patient Samples}

Archival cases of MCC were identified by a retrospective search for the diagnosis of Merkel cell carcinoma or neuroendocrine skin tumor in the Pathology Departments of the institutions. For cases where adequate tissue was available for analysis, the diagnosis was confirmed by an expert dermatopathologist (DK, KJB, or EYC) based on histopathology and immunostaining for diagnostic markers. After confirming a diagnosis of MCC and ensuring the sample was $>75 \%$ tumor, tissue was cut for DNA extraction. For each case, available patient information was retrieved by clinical chart review. De-identified tissue samples and clinical data were sent to the NIH for analysis.

We performed CNV analysis on 23 formalin-Fixed Paraffin-Embedded (FFPE) MCC tumor samples and 8 fresh-frozen MCC tumor samples. FFPE tumors were collected from patients at the University of Pennsylvania and Marshfield clinic between August 1996 and April 2012. Fresh-frozen tumors and normal tissues were collected from patients at Memorial Sloan Kettering between July 1995 and August 2010. Control tissues used for normalization consisted of 2 FFPE normal spleen samples (controls for the FFPE tumors) and 3 fresh-frozen normal tissues adjacent to excised tumors (controls for the fresh-frozen tumors).

\subsection{Genomic DNA Isolation}

Genomic DNA (gDNA) was extracted from FFPE or fresh-frozen tumor with QIAamp DNA FFPE Tissue kit (Qiagen, Hilden, Germany) or the DNeasy Blood and Tissue kit (Qiagen, Hilden, Germany) respectively, according to the manufacturer protocols. Samples were treated with RNase A (Qiagen, Hilden, Germany) per manufacturer protocol. DNA concentration, 260/280 and 260/230 nm ratios were measured on a DeNovix DS-11 spectrophotometer (DeNovix Inc., Wilmington, DE, USA) prior to DNA fragmentation with Alu1 restriction endonuclease. Following Alu1 restriction digestion, fragmented DNA was analyzed on a 2100 Agilent Bioanalyzer (Agilent Technologies, Santa Clara, CA, USA). Representative electropherograms and gel images of Alu1 digested DNA from FFPE and fresh frozen samples can be found in Figure S2.

\subsection{Virus Detection}

Nested qPCR was used to detect the presence of the Merkel cell polyomavirus from gDNA. For step one, $20 \mathrm{ng}$ of gDNA underwent 15 cycles of amplification with forward primer GGCAACATCCCTCTGATGAAAGC $3^{\prime}$ and reverse primer $5^{\prime}$ CCACCAGTCAAAACTTTCCCAAGTAGG $3^{\prime}$ using the KAPA2G Fast HotSStart PCR kit according to the manufacture protocol (Kapa Biosystems, Wilmington, MA, USA). Step two, $2 \mu \mathrm{L}$ of step one product was amplified for 25 cycles in a OneStep Real-Time PCR System with forward primer $5^{\prime}$ CTTAAAGCATCACCCTGATAAAGG $3^{\prime}$ and reverse primer $5^{\prime}$ AAACCAAAGAATAAAGCACTGATAGCA $3^{\prime}$ using Power SYBR green master mix as per the manufacture protocol (ThermoFisher, Carlsbad, CA, USA). Primer set (forward $5^{\prime}$ CCACACTGCCCATCTCGGAGAC $3^{\prime}$ and reverse $5^{\prime}$ GCGGTGAGGTCCCTACGGCCTG $\left.3^{\prime}\right)$ for TPO was used as an endogenous control for quantitative PCR. gDNA from the VP-MCC cell line MKL1 and VN-MCC cell line UISO were used as controls to determine the presence or absences of the polyomavirus. 


\subsection{Cell Lines}

UISO-MCC-1 [64] and MKL-1 [65] were previously described and grown in RPMI1640 supplemented with $10 \%$ fetal bovine serum and 1\% streptomycin/penicillin. Cell lines are sent out annually to be tested for authenticity via the Hum 16-Marker STR profile, interspecies contamination test and PCR evaluation for viruses and Mycoplasma which was performed by Idexx Bio Research.

\subsection{Nanostring Prep and Run}

A total of $600 \mathrm{ng}$ of gDNA was process for Nanostring nCounter copy number variants as per the manufacturer protocol (Nanostring Technologies, Seattle, WA, USA).

\subsection{Nanostring Data Analysis}

Copy number for 86 genes for each tumor sample compared to the appropriate control samples were determined in nSolver according to manufacturer instructions. A heatmap of the normalized copy number data was generated in $\mathrm{R}$ using the gplots package and heatmap. 2 code.

All statistical analyses were performed in GraphPad Prism (GraphPad Software, La Jolla, CA, USA). For each comparison, Grubbs' Method was used to detect statistical outliers. For populations with normal distributions, $T$-test or one-way ANOVA were performed to assess differences between VP-MCC and VN-MCC or between clusters. For populations with statistical outliers, Mann-Whitney or Kruskal-Wallis test were performed to assess differences between VP-MCC and VN-MCC or between clusters. Significance was based on a $p$-value of less than 0.05 .

\section{Conclusions}

We identified three distinct CNV signatures in MCC tumors. The observation that majority of MCC tumors demonstrate the Del structural signature, independent of virus status, suggests a shared pattern of genomic instability among most VP-MCC and VNMCC tumors that promotes allelic deletions. In contrast, a subset of MCC tumors appear to be associated with mechanisms that promote genomic amplifications. A further subset of VP-MCC tumors are capable of progression with very few genomic structural alterations. As VP-MCC are known to have a very low somatic mutational burden, observing VP-MCC tumors with few CNVs suggests that viral oncogenes and epigenetic changes may be sufficient for tumorigenesis. Although the different $\mathrm{CNV}$ signatures were not associated with survival differences in MCC patients, the signatures were associated with recurrent changes in specific cancer pathways. It is possible that testing genomic structural signatures may help identify MCC patients more likely to respond to targeted therapeutic approaches.

Supplementary Materials: The following are available online at https:/ / www.mdpi.com/2072-6 694/13/5/1134/s1, Figure S1: The three genomic structural variant clusters are not predictors of overall survival, Figure S2: Bioanalyzer analysis of Alu1 cut DNA from FFPE and fresh frozen MCC tumor samples, Table S1: Normalized genomic copy number at 86 gene loci for MCC tumor samples.

Author Contributions: Conceptualization, C.G. and I.B.; Formal analysis, N.T.H.; Funding acquisition, I.B.; Investigation, N.T.H.; Methodology, N.T.H., D.K., K.J.B. and E.Y.C.; Project administration, I.B.; Resources, D.K., K.J.B., E.Y.C. and C.G.; Supervision, I.B.; Visualization, N.T.H.; Writing—original draft, N.T.H.; Writing-review and editing, N.T.H., C.G. and I.B. All authors have read and agreed to the published version of the manuscript.

Funding: This work was supported by funding from the Intramural Research Program, Center for Cancer Research, National Cancer Institute (ZIA BC 011394 to I.B.) and the Marshfield Clinic Research Institute.

Institutional Review Board Statement: This retrospective investigation of deidentified data was carried out following the rules of the Declaration of Helsinki of 1975, revised in 2013. 
Informed Consent Statement: Analysis of patient samples from the three institutions was conducted under National Cancer Institute (NCI) Protocol 13CN024 without obtaining further consent as the samples were analyzed anonymously.

Data Availability Statement: Data is contained within the article or supplementary material.

Acknowledgments: The opinions expressed in this article are the authors' own and do not reflect the view of the National Institutes of Health, the Department of Health and Human Services, or the United States government. We would like to thank Emily Andrea for her editorial guidance.

Conflicts of Interest: We have no conflict of interest to declare.

\section{References}

1. Albores-Saavedra, J.; Batich, K.; Chable-Montero, F.; Sagy, N.; Schwartz, A.M.; Henson, D.E. Merkel cell carcinoma demographics, morphology, and survival based on 3870 cases: A population-based study. J. Cutan. Pathol. 2010, 37, 20-27. [CrossRef] [PubMed]

2. Harms, P.W.; Harms, K.L.; Moore, P.S.; DeCaprio, J.A.; Nghiem, P.; Wong, M.K.; Brownell, I. International workshop on Merkle cell carcinoma research working. The biology and treatment of Merkel cell carcinoma: Current understanding and research priorities. Nat. Rev. Clin. Oncol. 2018, 15, 763-776. [CrossRef] [PubMed]

3. Schwartz, R.A.; Lambert, W.C. The Merkel cell carcinoma: A 50-year retrospect. J. Surg. Oncol. 2005, 89, 5. [CrossRef] [PubMed]

4. Fitzgerald, T.L.; Dennis, S.; Kachare, S.D.; Vohra, N.A.; Wong, J.H.; Zervos, E.E. Dramatic increase in the incidence and mortality from Merkel cell carcinoma in the United States. Am. Surg. 2015, 81, 802-806. [CrossRef]

5. van Veenendaal, L.M.; van Akkooi, A.C.J.; Verhoef, C.; Grunhagen, D.J.; Klop, W.M.C.; Valk, G.D.; Tesselaar, M.E.T. Merkel cell carcinoma: Clinical outcome and prognostic factors in 351 patients. J. Surg. Oncol. 2018, 117, 1768-1775. [CrossRef] [PubMed]

6. Feng, H.; Shuda, M.; Chang, Y.; Moore, P.S. Clonal integration of a polyomavirus in human Merkel cell carcinoma. Science 2008, 319, 1096-1100. [CrossRef] [PubMed]

7. Harms, P.W. Update on Merkel cell carcinoma. Clin. Lab. Med. 2017, 37, 485-501. [CrossRef]

8. Al-Rohil, R.N.; Milton, D.R.; Nagarajan, P.; Curry, J.L.; Feldmeyer, L.; Torres-Cabala, C.A.; Ivan, D.; Prieto, V.G.; Tetzlaff, M.T.; Aung, P.P. Intratumoral and peritumoral lymphovascular invasion detected by D2-40 immunohistochemistry correlates with metastasis in primary cutaneous Merkel cell carcinoma. Hum. Pathol. 2018, 77, 98-107. [CrossRef]

9. Aung, P.P.; Parra, E.R.; Barua, S.; Sui, D.; Ning, J.; Mino, B.; Ledesma, D.A.; Curry, J.L.; Nagarajan, P.; Torres-Cabala, C.A.; et al. B7-H3 Expression in Merkel cell carcinoma-associated endothelial cells correlates with locally aggressive primary tumor features and increased vascular density. Clin. Cancer Res. 2019, 25, 3455-3467. [CrossRef] [PubMed]

10. Feldmeyer, L.; Hudgens, C.W.; Ray-Lyons, G.; Nagarajan, P.; Aung, P.P.; Curry, J.L.; Torres-Cabala, C.A.; Mino, B.; RodriguezCanales, J.; Reuben, A.; et al. Density, distribution, and composition of immune infiltrates correlate with survival in Merkel cell carcinoma. Clin. Cancer Res. 2016, 22, 5553-5563. [CrossRef] [PubMed]

11. Harms, P.W.; Patel, R.M.; Verhaegen, M.E.; Giordano, T.J.; Nash, K.T.; Johnson, C.N.; Daignault, S.; Thomas, D.G.; Gudjonsson, J.E.; Elder, J.T.; et al. Distinct gene expression profiles of viral- and nonviral-associated merkel cell carcinoma revealed by transcriptome analysis. J. Investig. Dermatol. 2013, 133, 936-945. [CrossRef] [PubMed]

12. Wang, L.; Harms, P.W.; Palanisamy, N.; Carskadon, S.; Cao, X.; Siddiqui, J.; Patel, R.M.; Zelenka-Wang, S.; Durham, A.B.; Fullen, D.R.; et al. Age and gender associations of virus positivity in Merkel cell carcinoma characterized using a novel RNA in situ hybridization assay. Clin. Cancer Res. 2017, 23, 5622-5630. [CrossRef]

13. Goh, G.; Walradt, T.; Markarov, V.; Blom, A.; Riaz, N.; Doumani, R.; Stafstrom, K.; Moshiri, A.; Yelistratova, L.; Levinsohn, J.; et al. Mutational landscape of MCPyV-positive and MCPyV-negative Merkel cell carcinomas with implications for immunotherapy. Oncotarget 2016, 7, 3403-3415. [CrossRef]

14. Harms, P.W.; Collie, A.M.; Hovelson, D.H.; Cani, A.K.; Verhaegen, M.E.; Patel, R.M.; Fullen, D.R.; Omata, K.; Dlugosz, A.A.; Tomlins, S.A.; et al. Next generation sequencing of Cytokeratin 20-negative Merkel cell carcinoma reveals ultraviolet-signature mutations and recurrent TP53 and RB1 inactivation. Mod. Pathol. 2016, 29, 240-248. [CrossRef] [PubMed]

15. Wong, S.Q.; Waldeck, K.; Vergara, I.A.; Schroder, J.; Madore, J.; Wilmott, J.S.; Colebatch, A.J.; De Paoli-Iseppi, R.; Li, J.; Lupat, R.; et al. UV-associated mutations underlie the etiology of MCV-negative merkel cell carcinomas. Cancer Res. 2015, 75, 5228-5234. [CrossRef] [PubMed]

16. Veija, T.; Sarhadi, V.K.; Koljonen, V.; Bohling, T.; Knuutila, S. Hotspot mutations in polyomavirus positive and negative Merkel cell carcinomas. Cancer Genet. 2016, 209, 30-35. [CrossRef]

17. Kwun, H.J.; Shuda, M.; Feng, H.; Camacho, C.J.; Moore, P.S.; Chang, Y. Merkel cell polyomavirus small T antigen controls viral replication and oncoprotein expression by targeting the cellular ubiquitin ligase SCFFbw7. Cell Host Microbe 2013, 14, 125-135. [CrossRef] [PubMed]

18. Shuda, M.; Kwun, H.J.; Feng, H.; Chang, Y.; Moore, P.S. Human Merkel cell polyomavirus small T antigen is an oncoprotein targeting the 4E-BP1 translation regulator. J. Clin. Investig. 2011, 121, 3623-3634. [CrossRef] [PubMed]

19. Abdul-Sada, H.; Muller, M.; Mehta, R.; Toth, R.; Arthur, J.S.C.; Whitehouse, A.; Macdonald, A. The PP4R1 sub-unit of protein phosphatase PP4 is essential for inhibition of NF-kappaB by merkel polyomavirus small tumour antigen. Oncotarget 2017, 8, 25418-25432. [CrossRef] 
20. Van Gele, M.; Leonard, J.H.; Van Roy, N.; Van Limbergen, H.; Van Belle, S.; Cocquyt, V.; Salwen, H.; De Paepe, A.; Speleman, F. Combined karyotyping, CGH and M-FISH analysis allows detailed characterization of unidentified chromosomal rearrangements in Merkel cell carcinoma. Int. J. Cancer 2002, 101, 137-145. [CrossRef] [PubMed]

21. Starrett, G.J.; Thakuria, M.; Chen, T.; Marcelus, C.; Cheng, J.; Nomburg, J.; Thorner, A.R.; Slevin, M.K.; Powers, W.; Burns, R.T.; et al. Clinical and molecular characterization of virus-positive and virus-negative Merkel cell carcinoma. Genome Med. 2020, 12, 30. [CrossRef] [PubMed]

22. Evan, G.I.; Vousden, K.H. Proliferation, cell cycle and apoptosis in cancer. Nature 2001, 411, 342-348. [CrossRef] [PubMed]

23. Hartwell, L. Defects in a cell cycle checkpoint may be responsible for the genomic instability of cancer cells. Cell 1992, 71, 543-546. [CrossRef]

24. Limpose, K.L.; Trego, K.S.; Li, Z.; Leung, S.W.; Sarker, A.H.; Shah, J.A.; Ramalingam, S.S.; Werner, E.M.; Dynan, W.S.; Cooper, P.K.; et al. Overexpression of the base excision repair NTHL1 glycosylase causes genomic instability and early cellular hallmarks of cancer. Nucleic Acids Res. 2018, 46, 4515-4532. [CrossRef] [PubMed]

25. Garneski, K.M.; DeCaprio, J.A.; Nghiem, P. Does a new polyomavirus contribute to Merkel cell carcinoma? Genome Biol. 2008, 9 , 228. [CrossRef] [PubMed]

26. Popp, S.; Waltering, S.; Herbst, C.; Moll, I.; Boukamp, P. UV-B-type mutations and chromosomal imbalances indicate common pathways for the development of Merkel and skin squamous cell carcinomas. Int. J. Cancer 2002, 99, 352-360. [CrossRef]

27. Hartschuh, W.; Schulz, T. Merkel cell hyperplasia in chronic radiation-damaged skin: Its possible relationship to fibroepithelioma of Pinkus. J. Cutan. Pathol. 1997, 24, 477-483. [CrossRef]

28. Miller, R.W.; Rabkin, C.S. Merkel cell carcinoma and melanoma: Etiological similarities and differences. Cancer Epidemiol. Biomark. Prev. 1999, 8, 153-158.

29. Agelli, M.; Clegg, L.X. Epidemiology of primary Merkel cell carcinoma in the United States. J. Am. Acad. Dermatol. 2003, 49, 832-841. [CrossRef]

30. Brenner, B.; Sulkes, A.; Rakowsky, E.; Feinmesser, M.; Yukelson, A.; Bar-Haim, E.; Katz, A.; Idelevich, E.; Neuman, A.; Barhana, M.; et al. Second neoplasms in patients with Merkel cell carcinoma. Cancer 2001, 91, 1358-1362. [CrossRef]

31. Ratner, D.; Nelson, B.R.; Brown, M.D.; Johnson, T.M. Merkel cell carcinoma. J. Am. Acad. Dermatol. 1993, 29, 143-156. [CrossRef]

32. Cerroni, L.; Kerl, H. Primary cutaneous neuroendocrine (Merkel cell) carcinoma in association with squamous- and basal-cell carcinoma. Am. J. Dermatopathol. 1997, 19, 610-613. [CrossRef] [PubMed]

33. Aydin, A.; Kocer, N.E.; Bekerecioglu, M.; Sari, I. Cutaneous undifferentiated small (Merkel) cell carcinoma, that developed synchronously with multiple actinic keratoses, squamous cell carcinomas and basal cell carcinoma. J. Dermatol. 2003, 30, 241-244. [CrossRef] [PubMed]

34. Pulitzer, M.P.; Brannon, A.R.; Berger, M.F.; Louis, P.; Scott, S.N.; Jungbluth, A.A.; Coit, D.G.; Brownell, I.; Busam, K.J. Cutaneous squamous and neuroendocrine carcinoma: Genetically and immunohistochemically different from Merkel cell carcinoma. Mod. Pathol. 2015, 28, 1023-1032. [CrossRef]

35. Iacocca, M.V.; Abernethy, J.L.; Stefanato, C.M.; Allan, A.E.; Bhawan, J. Mixed Merkel cell carcinoma and squamous cell carcinoma of the skin. J. Am. Acad. Dermatol. 1998, 39, 882-887. [CrossRef]

36. Panich, U.; Sittithumcharee, G.; Rathviboon, N.; Jirawatnotai, S. Ultraviolet radiation-induced skin aging: The role of DNA damage and oxidative stress in epidermal stem cell damage mediated skin aging. Stem. Cells Int. 2016, 2016, 7370642. [CrossRef]

37. Morales-Sanchez, A.; Fuentes-Panana, E.M. Human viruses and cancer. Viruses 2014, 6, 4047-4079. [CrossRef]

38. Heath, M.; Jaimes, N.; Lemos, B.; Mostaghimi, A.; Wang, L.C.; Penas, P.F.; Nghiem, P. Clinical characteristics of Merkel cell carcinoma at diagnosis in 195 patients: The AEIOU features. J. Am. Acad. Dermatol. 2008, 58, 375-381. [CrossRef] [PubMed]

39. Cancer Genome Atlas Network. Comprehensive molecular portraits of human breast tumours. Nature 2012, 490, 61-70. [CrossRef] [PubMed]

40. Phillips, S.M.; Barton, C.M.; Lee, S.J.; Morton, D.G.; Wallace, D.M.; Lemoine, N.R.; Neoptolemos, J.P. Loss of the retinoblastoma susceptibility gene (RB1) is a frequent and early event in prostatic tumorigenesis. Br. J. Cancer 1994, 70, 1252-1257. [CrossRef]

41. Phillips, S.M.; Morton, D.G.; Lee, S.J.; Wallace, D.M.; Neoptolemos, J.P. Loss of heterozygosity of the retinoblastoma and adenomatous polyposis susceptibility gene loci and in chromosomes 10p, 10q and 16q in human prostate cancer. Br. J. Urol. 1994, 73, 390-395. [CrossRef]

42. Bettendorf, O.; Schmidt, H.; Staebler, A.; Grobholz, R.; Heinecke, A.; Boecker, W.; Hertle, L.; Semjonow, A. Chromosomal imbalances, loss of heterozygosity, and immunohistochemical expression of TP53, RB1, and PTEN in intraductal cancer, intraepithelial neoplasia, and invasive adenocarcinoma of the prostate. Genes Chromosom. Cancer 2008, 47, 565-572. [CrossRef]

43. Dimaras, H.; Khetan, V.; Halliday, W.; Orlic, M.; Prigoda, N.L.; Piovesan, B.; Marrano, P.; Corson, T.W.; Eagle, R.C., Jr.; Squire, J.A.; et al. Loss of RB1 induces non-proliferative retinoma: Increasing genomic instability correlates with progression to retinoblastoma. Hum. Mol. Genet. 2008, 17, 1363-1372. [CrossRef]

44. Xing, F.; Persaud, Y.; Pratilas, C.A.; Taylor, B.S.; Janakiraman, M.; She, Q.B.; Gallardo, H.; Liu, C.; Merghoub, T.; Hefter, B.; et al. Concurrent loss of the PTEN and RB1 tumor suppressors attenuates RAF dependence in melanomas harboring (V600E)BRAF. Oncogene 2012, 31, 446-457. [CrossRef] [PubMed]

45. Hesbacher, S.; Pfitzer, L.; Wiedorfer, K.; Angermeyer, S.; Borst, A.; Haferkamp, S.; Scholz, C.J.; Wobser, M.; Schrama, D.; Houben, R. RB1 is the crucial target of the Merkel cell polyomavirus Large T antigen in Merkel cell carcinoma cells. Oncotarget 2016, 7, 32956-32968. [CrossRef] [PubMed] 
46. Nakamura, T.; Sato, Y.; Watanabe, D.; Ito, H.; Shimonohara, N.; Tsuji, T.; Nakajima, N.; Suzuki, Y.; Matsuo, K.; Nakagawa, H.; et al. Nuclear localization of Merkel cell polyomavirus large T antigen in Merkel cell carcinoma. Virology 2010, 398, 273-279. [CrossRef] [PubMed]

47. Dresang, L.R.; Guastafierro, A.; Arora, R.; Normolle, D.; Chang, Y.; Moore, P.S. Response of Merkel cell polyomavirus-positive merkel cell carcinoma xenografts to a survivin inhibitor. PLoS ONE 2013, 8, e80543. [CrossRef]

48. Xu, X.; Weaver, Z.; Linke, S.P.; Li, C.; Gotay, J.; Wang, X.W.; Harris, C.C.; Ried, T.; Deng, C.X. Centrosome amplification and a defective G2-M cell cycle checkpoint induce genetic instability in BRCA1 exon 11 isoform-deficient cells. Mol. Cell 1999, 3, 389-395. [CrossRef]

49. Keyomarsi, K.; Pardee, A.B. Redundant cyclin overexpression and gene amplification in breast cancer cells. Proc. Natl. Acad. Sci. USA 1993, 90, 1112-1116. [CrossRef]

50. Paulson, K.G.; Lemos, B.D.; Feng, B.; Jaimes, N.; Penas, P.F.; Bi, X.; Maher, E.; Cohen, L.; Leonard, J.H.; Granter, S.R.; et al. Array-CGH reveals recurrent genomic changes in Merkel cell carcinoma including amplification of L-Myc. J. Investig. Dermatol. 2009, 129, 1547-1555. [CrossRef]

51. Kim, D.W.; Wu, N.; Kim, Y.C.; Cheng, P.F.; Basom, R.; Kim, D.; Dunn, C.T.; Lee, A.Y.; Kim, K.; Lee, C.S.; et al. Genetic requirement for Mycl and efficacy of RNA Pol I inhibition in mouse models of small cell lung cancer. Genes Dev. 2016, 30, 1289-1299. [CrossRef] [PubMed]

52. Shao, Q.; Byrum, S.D.; Moreland, L.E.; Mackintosh, S.G.; Kannan, A.; Lin, Z.; Morgan, M.; Stack, B.C., Jr.; Cornelius, L.A.; Tackett, A.J.; et al. A proteomic study of human Merkel cell carcinoma. J. Proteom. Bioinform. 2013, 6, 275-282. [CrossRef] [PubMed]

53. Lin, Z.; McDermott, A.; Shao, L.; Kannan, A.; Morgan, M.; Stack, B.C., Jr.; Moreno, M.; Davis, D.A.; Cornelius, L.A.; Gao, L. Chronic mTOR activation promotes cell survival in Merkel cell carcinoma. Cancer Lett. 2014, 344, 272-281. [CrossRef]

54. Wu, D.W.; Lee, M.C.; Hsu, N.Y.; Wu, T.C.; Wu, J.Y.; Wang, Y.C.; Cheng, Y.W.; Chen, C.Y.; Lee, H. FHIT loss confers cisplatin resistance in lung cancer via the AKT/NF-kappaB/Slug-mediated PUMA reduction. Oncogene 2015, 34, 3882-3883. [CrossRef]

55. Semba, S.; Trapasso, F.; Fabbri, M.; McCorkell, K.A.; Volinia, S.; Druck, T.; Iliopoulos, D.; Pekarsky, Y.; Ishii, H.; Garrison, P.N.; et al. Fhit modulation of the Akt-survivin pathway in lung cancer cells: Fhit-tyrosine 114 (Y114) is essential. Oncogene 2006, 25, 2860-2872. [CrossRef] [PubMed]

56. Weiske, J.; Albring, K.F.; Huber, O. The tumor suppressor Fhit acts as a repressor of beta-catenin transcriptional activity. Proc. Natl. Acad. Sci. USA 2007, 104, 20344-20349. [CrossRef]

57. Robertson, B.W.; Chellaiah, M.A. Osteopontin induces beta-catenin signaling through activation of Akt in prostate cancer cells. Exp. Cell. Res. 2010, 316,1-11. [CrossRef]

58. He, X.C.; Zhang, J.; Tong, W.G.; Tawfik, O.; Ross, J.; Scoville, D.H.; Tian, Q.; Zeng, X.; He, X.; Wiedemann, L.M.; et al. BMP signaling inhibits intestinal stem cell self-renewal through suppression of Wnt-beta-catenin signaling. Nat. Genet. 2004, 36, 1117-1121. [CrossRef]

59. Masugi, Y.; Yamazaki, K.; Emoto, K.; Effendi, K.; Tsujikawa, H.; Kitago, M.; Itano, O.; Kitagawa, Y.; Sakamoto, M. Upregulation of integrin beta4 promotes epithelial-mesenchymal transition and is a novel prognostic marker in pancreatic ductal adenocarcinoma. Lab. Investig. 2015, 95, 308-319. [CrossRef]

60. Zheng, Y.; de la Cruz, C.C.; Sayles, L.C.; Alleyne-Chin, C.; Vaka, D.; Knaak, T.D.; Bigos, M.; Xu, Y.; Hoang, C.D.; Shrager, J.B.; et al. A rare population of CD24(+)ITGB4(+)Notch(hi) cells drives tumor propagation in NSCLC and requires Notch3 for self-renewal. Cancer Cell 2013, 24, 59-74. [CrossRef]

61. nanoString, Analyzing FFPE Specimens with the nCounter®Copy Number Variation (CNV) Assay. 2019. Available online: http:/ /108.166.79.23/products/CNV, nanoString Tech, https://www.nanostring.com/wp-content/uploads/2020/12/TN_MK1 113_FFPE_CNV_R3.pdf (accessed on 16 February 2021).

62. Do, H.; Dobrovic, A. Sequence artifacts in DNA from formalin-fixed tissues: Causes and strategies for minimization. Clin. Chem. 2015, 61, 64-71. [CrossRef] [PubMed]

63. Jakubek, Y.A.; Chang, K.; Sivakumar, S.; Yu, Y.; Giordano, M.R.; Fowler, J.; Huff, C.D.; Kadara, H.; Vilar, E.; Scheet, P. Large-scale analysis of acquired chromosomal alterations in non-tumor samples from patients with cancer. Nat. Biotechnol. 2020, 38, 90-96. [CrossRef]

64. Ronan, S.G.; Green, A.D.; Shilkaitis, A.; Huang, T.S.; Das Gupta, T.K. Merkel cell carcinoma: In vitro and in vivo characteristics of a new cell line. J. Am. Acad. Dermatol. 1993, 29, 715-722. [CrossRef]

65. Rosen, S.T.; Gould, V.E.; Salwen, H.R.; Herst, C.V.; Le Beau, M.M.; Lee, I.; Bauer, K.; Marder, R.J.; Andersen, R.; Kies, M.S.; et al. Establishment and characterization of a neuroendocrine skin carcinoma cell line. Lab. Investig. 1987, 56, 302-312. [PubMed] 